\title{
BMJ What is a disease? Perspectives of the open public, health professionals and legislators
}

\author{
Kari A O Tikkinen, ${ }^{1,2}$ Janne S Leinonen, ${ }^{3}$ Gordon H Guyatt, ${ }^{1,4}$ \\ Shanil Ebrahim, ${ }^{1}$ Teppo L N Järvinen ${ }^{5}$
}

To cite: Tikkinen KAO, Leinonen JS, Guyatt GH, et al. What is a disease? Perspectives of the public, health professionals and legislators. BMJ Open 2012;2:e001632. doi:10.1136/bmjopen-2012001632

- Prepublication history and additional material for this paper are available online. To view these files please visit the journal online (http://dx.doi.org/10.1136/ bmjopen-2012-001632).

Received 9 June 2012 Accepted 15 October 2012

This final article is available for use under the terms of the Creative Commons Attribution Non-Commercial 2.0 Licence; see http://bmjopen.bmj.com

For numbered affiliations see end of article.

Correspondence to Dr Kari AO Tikkinen; kari.tikkinen@fimnet.fi

\section{ABSTRACT}

Objective: To assess the perception of diseases and the willingness to use public-tax revenue for their treatment among relevant stakeholders.

Design: A population-based, cross-sectional mailed survey.

Setting: Finland.

Participants: 3000 laypeople, 1500 doctors, 1500 nurses (randomly identified from the databases of the Finnish Population Register, the Finnish Medical Association and the Finnish Nurses Association) and all 200 parliament members.

Main outcome measures: Respondents' perspectives on a five-point Likert scale on two claims on 60 states of being: '(This state of being) is a disease'; and '(This state of being) should be treated with public tax revenue'.

Results: Of the 6200 individuals approached, 3280 $(53 \%)$ responded. Of the 60 states of being, $\geq 80 \%$ of respondents considered 12 to be diseases (Likert scale responses of ' 4 ' and ' 5 ') and five not to be diseases (Likert scale responses of ' 1 ' and '2'). There was considerable variability in most states, and great variability in 10 ( $\geq 20 \%$ of respondents of all groups considered it a disease and $\geq 20 \%$ rejected as a disease). Doctors were more inclined to consider states of being as diseases than laypeople; nurses and members were intermediate $(p<0.001)$, but all groups showed large variability. Responses to the two claims were very strongly correlated $(r=0.96(95 \% \mathrm{Cl} 0.94$ to 0.98$) ; p<0.001$ ).

Conclusions: There is large disagreement among the public, health professionals and legislators regarding the classification of states of being as diseases and whether their management should be publicly funded. Understanding attitudinal differences can help to enlighten social discourse on a number of contentious public policy issues.

\section{INTRODUCTION}

Disease and illness are related concepts: patients suffer from 'illnesses' and doctors diagnose and treat 'diseases'. Illnesses are experiences of discontinuities in states of

\section{ARTICLE SUMMARY}

Article focus

- The concept of disease lies at the heart of medicine.

- No study has addressed perceptions of all relevant stakeholders on what, across a wide range of conditions, should be classified as a disease.

Key messages

- Our survey found large differences in the views among Finnish laypeople, doctors, nurses and parliament members regarding whether states of being should be considered diseases and be managed through public revenue.

- Although doctors were more inclined to consider states of being as diseases, disagreement was as evident among health professionals as in other groups.

- Understanding peoples' attitudes about whether states of being should be considered diseases elucidates fundamental underlying attitudes and thus can inform social discourse regarding a number of contentious public policy issues.

Strengths and limitations of this study

- This is the first study to assess whether states of being should be considered diseases and should be managed through public revenue using a broad sample of doctors, nurses, laypeople as well as legislators.

- Our results from the Finnish population may be less generalisable to less affluent countries and countries with different social and cultural values.

being and perceived role performances; when diagnosed as diseases, they are presumed abnormalities in the function or structure of body systems. Disease can refer to a combination of signs and symptoms, phenomena associated with a disorder of function or structure or illness associated with a specific cause $(\mathrm{s}){ }^{2}$ There are, however, no universally accepted criteria for establishing 'disease'. ${ }^{3-5}$ Indeed, the complexity of the concept of disease has led to the observation that it can be as difficult to define as beauty, truth or love. ${ }^{6}$ 
The concept of disease is subject to social, cultural and economic influences that have varied over time: these influences have been particularly evident in the last two decades. ${ }^{4}{ }^{5-9}$ During this time, we witnessed a growing tendency to classify states of being as diseases, a trend with important possible consequences, both positive and negative. ${ }^{8}{ }^{10-13}$ Possible positive consequences include the facilitation of patient-physician communication $^{4511}$ and increased willingness to use public money and thus enhance equality in the distribution of limited resources. ${ }^{4} 14$ Possible adverse consequences include making relatively healthy individuals perceive themselves as sick, encouraging misguided attempts to treat states that are part of the normal human condition, and individuals being denied employment or insurance. ${ }^{4} 11 \quad 15-17$ The extent to which health workers and the public have been influenced by these tendencies and their current perceptions remain uncertain.

Authors have also suggested that the disease label can be used as a social control mechanism. ${ }^{18-20}$ The 'sick role' theory suggests that illness disrupts normal social functioning, making the individual responsible for adhering to treatment regimes in order to maintain social productivity. $^{21-23}$ However, the relationship between the patient and the medical sphere exists within a socially constructed hierarchy wherein medical institutions ultimately hold the individual accountable for collective social problems. ${ }^{19} 2123$ When individual behaviour deviates from pre-established social norms, it is not the individual, but the medical community that labels, diagnoses and treats aberrant behaviour as a socially legitimated health condition. ${ }^{19}$

No earlier study assessed perceptions' on use of public funding, and only one study ${ }^{2}$ assessed perceptions' on the concept of disease over wider range of conditions.
Campbell et $a l^{2}$ found that doctors considered more noninfectious conditions to be diseases than laypeople. Because of the importance of the issue, and the paucity of empirical evidence regarding peoples' views, we conducted a survey of the general public, doctors, nurses and parliament members in Finland to determine the extent to which they considered 60 states of being to be diseases and their attitudes towards using public funds for managing these states. On the basis of differences in background, training, and life experience and underlying attitudes, we hypothesised that groups (laypeople, doctors, nurses and parliament members) would vary in their conceptions of disease, and that there would also be large variation in conceptions of disease within groups.

\section{METHODS}

\section{The Finnish Disease (FIND) Survey study population}

In 2010, we selected a random sample of 3000 laypeople, 1500 doctors, 1500 nurses and all the 200 members of the Parliament of Finland (MPs). We identified laypeople 18-75 years of age from the Finnish Population Register Centre, and doctors and nurses less than 65 years of age from the registers of the Finnish Medical Association and the Finnish Nurses Association. We excluded individuals who had died, emigrated, were deemed seriously disabled or who changed careers and would therefore no longer be members of their respective group (figure 1).

\section{Survey}

Referring to the existing literature and the International Classification of Diseases (ICD-10), ${ }^{2} 112425$ we chose, through iterative discussion and consensus-building, 60 states of being that we considered familiar to the
Figure 1 Study flow. We randomised the 60 states of being into three blocks: version $A$ consisted of three blocks (each consisting of 20 states of being) in the order $1-2-3$, version $B$ in the order 3-1-2 and version $C$ in the order 2-3-1.

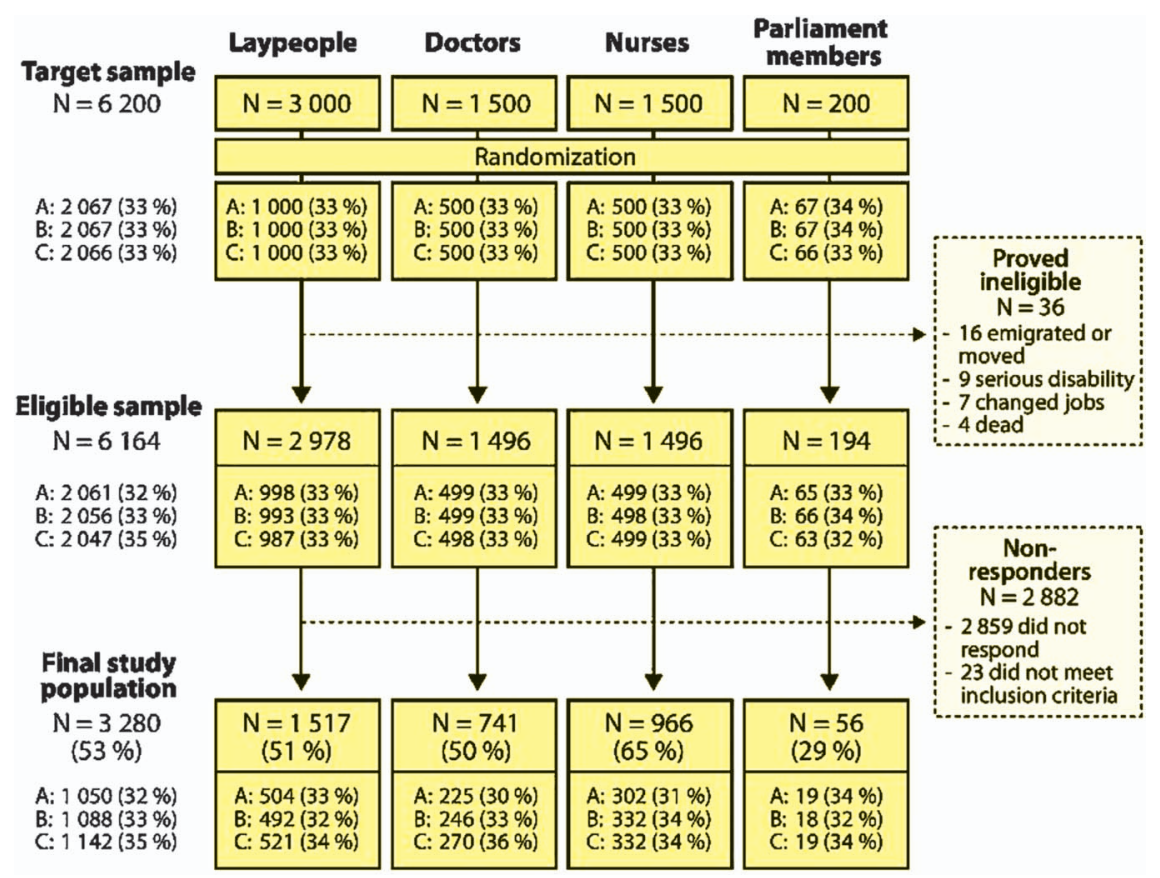


relevant stakeholders. We anticipated that everyone would consider some of these states a disease, none would consider some states a disease, and that some states might elicit disagreement (see online supplementary figures A1 and A2 in the appendix). We asked participants to respond to two claims: (1) '(This state of being) is a disease' (claim A) and (2) '(This state of being) should be treated with public tax revenue' (claim B) on a five-point Likert scale ranging from strongly disagree to strongly agree (see online supplementary figures A1 and A2 in appendix). We elicited demographic information using questions from earlier surveys (see online supplementary table A1 in the appendix). We pilot tested the questionnaire with 20 laypeople and five doctors, and made minor revisions on the basis of feedback.

We mailed the questionnaires in June 2010 and sent reminders in August and October 2010. We made precontacts with MPs by email and telephone. The ethics committee of the Pirkanmaa Hospital District in Finland granted exemption from ethical review (R11110). The reporting of the study conforms to the STROBE statement. ${ }^{26}$

\section{Randomisation and exclusion criteria}

Each participant received a questionnaire eliciting responses to 60 states of being. We randomised the 60 states of being into three blocks (1, 2 and 3; each containing 20 states). We created three versions of the questionnaire: version A consisted of blocks in the order 1-2-3, version $B$ in the order 3-1-2 and version $C$ in the order 2-3-1. Within each sample group (laypeople, doctors, nurses and MPs), we randomised respondents to the three versions (figure 1).

To check comprehension of the questionnaire, we placed three states (myocardial infarction, pneumonia and breast cancer) likely to be considered as disease as the first state of being in each block. Respondents who did not agree to some extent or strongly agree to the statement '(This state of being) is a disease' (see online supplementary figures A1 and A2 in appendix) for any of these three were deemed unlikely to understand the questionnaire and excluded from the analyses (figure 1).

\section{Statistical analysis}

For each group (doctors, nurses, laypeople and MPs), we calculated the proportion of states of being where respondents strongly agreed or agreed to some extent regarding the two claims. Using a Pearson $\chi^{2}$ test on all possible pair-wise comparisons (altogether six comparisons for each state of being by claim), we evaluated the order of ratings of the perception of disease and expenditure of public tax revenue claims across groups. We calculated the correlation between the proportions of individuals who either strongly agreed or agreed to some extent across states in the two claims. All other analyses were descriptive.

\section{RESULTS}

Of the 6200 people approached, $3280(53.2 \%)$ participated, of whom 36 proved ineligible (figure 1). Of the 3244 eligible individuals who completed and understood the questionnaire, $3246(99 \%)$ responded to at least 55 of the 60 states of being. Among respondents, the mean (SD) age was: laypeople 49.5 (15.5), doctors 46.1 (10.7), nurses 44.9 (11.3) and MPs 54.4 (9.8). There were significantly more women among nurses $(97.3 \%)$, and fewer among MPs (35.7\%) compared with doctors $(61.5 \%)$ or laypeople $(57.3 \%) \quad(p<0.01$ for all comparisons). We found no significant differences in ratings or background characteristics between questionnaire versions and individuals responding at different response rounds. Online supplementary table A1 in the appendix presents the demographic data.

From the 60 states of being, 12 were perceived as diseases by $\geq 80 \%$ of respondents from all groups and five were perceived not to be diseases by $\geq 80 \%$ (figure 2 and table 1). Doctors were most likely to consider states of being as diseases followed by nurses, MPs and laypeople $(p<0.001$ for all pairwise comparisons). For a large number of states, there was extreme disagreement regarding classification as a disease among all study groups (figure 2). In 10 states, $\geq 20 \%$ of participants considered them diseases and $\geq 20 \%$ did not (table 1 ). There was a very strong correlation between responses to claims ( $\mathrm{r}=0.96$ (95\% CI 0.94 to 0.98 ); $\mathrm{p}<0.001$; no differences between groups) (see online supplementary figure A3 in the appendix).

\section{DISCUSSION}

\section{Statement of principal findings}

Our survey found large discrepancies in the views among laypeople, doctors, nurses and MPs in Finland regarding whether states of being should be considered diseases and should be managed through public revenue. Although physicians were more inclined to consider states of being as diseases, disagreement was as evident among health professionals as in other groups (figure 2 and table 1). In all groups, willingness to pay for treatment from public funds was very strongly correlated with the perception of disease.

\section{Strengths and limitations}

The strengths of our study include a large sample of both healthcare professionals and general population, an acceptable response rate, excellent completeness of questionnaires and a large number of states of being that elicited a wide range of responses. Further, the sample proved similar in its characteristics to the target populations in terms of age and gender distribution, education, employment and marital status (for details, see online supplementary table A1 in the appendix and its supplementary references). We found no trend in the perceptions or participants' characteristics by response round, reducing concern regarding selection bias. 


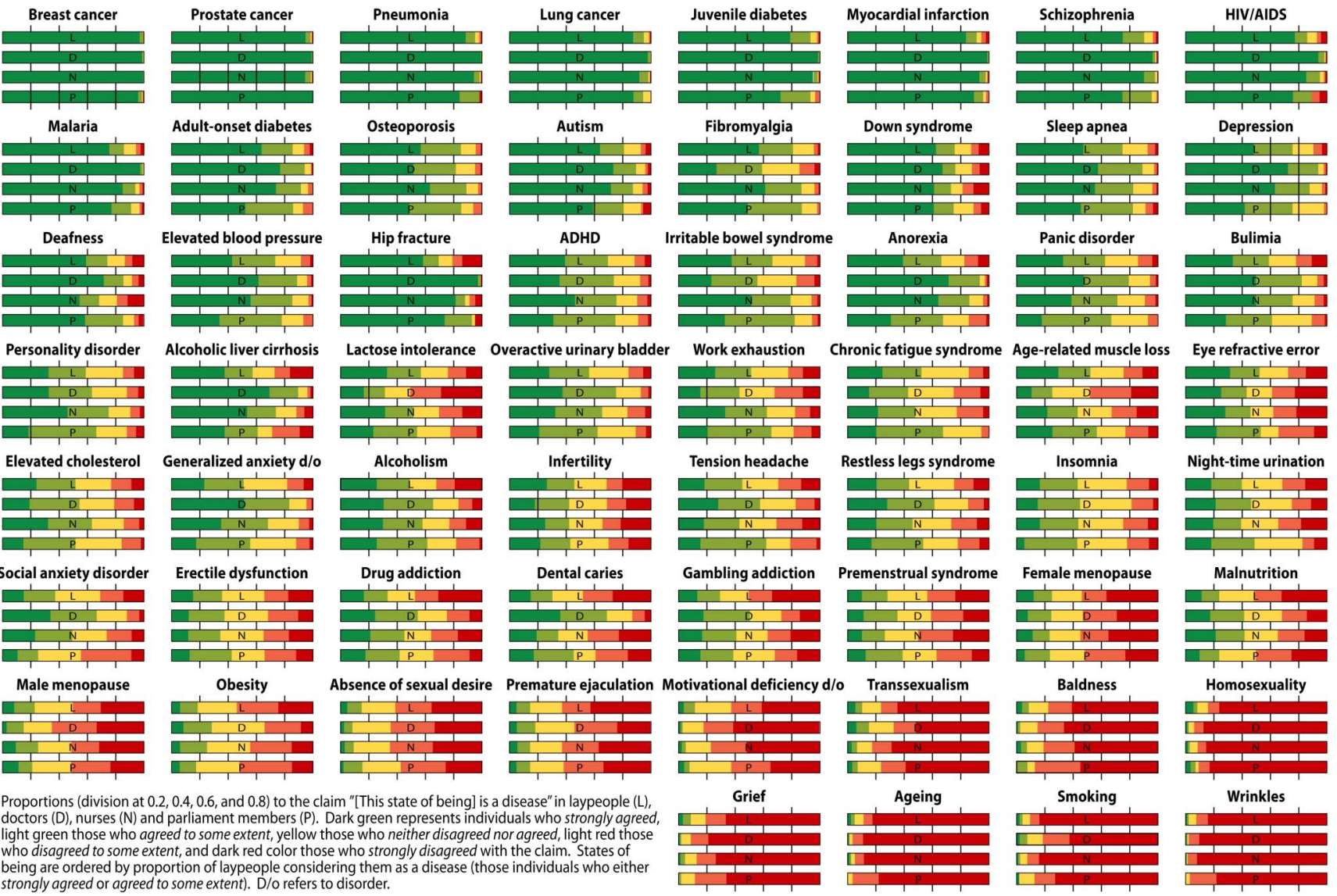

Figure 2 Variation of perceptions in the concept of disease among laypeople, doctors, nurses and members of parliament.

The limitations of our study include concern that the strong correlation between the claims may be partly caused by the positioning of questions adjacent to one another in the questionnaire. Second, these results from the Finnish population may be less generalisable to less affluent countries and those with different social and cultural values. For instance, the high correlation between the disease label and the willingness to fund

Table 1 (A) States of being perceived as a disease by at least $80 \%$ of respondents of all groups, (B) states of being not perceived as a disease by at least $80 \%$ of respondents of all groups and (C) states of being perceived as a disease by at least $20 \%$ and not as a disease by at least another $20 \%$ of respondents of all groups (laypeople, doctors, nurses and parliament members)

(A) Perceived as disease by more than $80 \%$ (response options ' 4 ' and ' 5 ')

Breast cancer

Prostate cancer

Pneumonia

Lung cancer

Juvenile diabetes

Myocardial infarction

(B) Not perceived as disease by more than $80 \%$ (response options ' 1 ' and '2')

Wrinkles

Smoking

Ageing

(C) At least $20 \%$ perceived as disease (response options ' 4 ' and ' 5 ') and at least another $20 \%$ did not perceive as disease (response options ' 1 ' and ' 2 ')

Premenstrual syndrome, PMS

Erectile dysfunction

Gambling addiction

Infertility

Drug addiction
Schizophrenia

HIV/AIDS

Malaria

Adult-onset diabetes

Osteoporosis

Autism

Grief

Homosexuality 
socially may be related to Finland's high level of social solidarity. Finland is said to have a strong welfare state, and the high correlation between claims may not be reproduced in other jurisdictions. Third, despite our attempt to address understanding and the potential impact of wording in a pilot study, there is a possibility that a framing effect (ie, individuals reacting differently to a particular response depending on how the question is worded) may have occurred. There is evidence from various populations illustrating the impact of framing on decision-making and preferences. ${ }^{27-29}$ In particular, this may have been an issue for our claim $B$, whether states of being should be funded by public revenue; an alternative framing of questions may have elicited different results. $^{30}$

\section{Comparison with other studies}

Some investigators have addressed patients' and healthcare providers' perceptions regarding the disease concept and use of public funding in specific conditions. ${ }^{31-34}$ However, no earlier study assessed perceptions' on use of public funding over a wider range of conditions, and only one study assessed perceptions' of the disease concept. ${ }^{2}$ In keeping with our finding that physicians were slightly more likely than others to consider states of being to be diseases, Campbell et $a t^{2}$ found no difference among non-medical faculty, secondary school students, academic internists and general practitioners on how they perceived illnesses due to infections, but found that doctors considered more noninfectious conditions to be diseases.

In another related investigation, the editorial board of the $B M J$ and its readers identified a list of almost 200 non-diseases (defined as 'a human process or problem that some have defined as a medical condition but where people may have better outcomes if the problem or process was not defined in that way') including ageing, baldness and boredom. ${ }^{11}$ As in our survey, there was considerable variation in the states of being deemed 'non-diseases'.

\section{Meaning of the study: possible explanations and implications}

The concept of 'disease' lies at the heart of medicine, ${ }^{7} 14$ defining its domain and its role in public policy, including the range of conditions in which sufferers may be entitled to public funding for their treatment. ${ }^{35-37}$ Building on earlier work, ${ }^{4} 811$ 13-17 38-48 table 2 presents a taxonomy of states of being, exploring the relation between categorisation -or not - as a disease, the implications for action and potential negative consequences. The issues presented in table 2 are subjects of ongoing, often heated, debate. Our results (ie, large differences in views whether states of being should be considered diseases and should be managed through public revenue) provide insight into these debates: why they are so contentious is due at least in part to disparities in views on the fundamental nature of these states of being. Our study represents only the first steps in understanding the concept of 'disease'. Additional qualitative studies would be useful for obtaining further insight into interpretation of the findings.

As reflected in table 2, people tend to think of diseases as conditions for which individuals do not bear primary responsibility, afflictions of which the sufferer is at least to some extent a victim. ${ }^{34}$ Thus, if we view addictions as diseases (which substantial proportions of our respondents did, and did not) we are inclined to look for solutions through harm reduction approaches and medical treatment, and to allocate public funding for these interventions. ${ }^{42}{ }^{48}$ Alternative views include viewing a condition as a moral failing, bad habit or retribution for bad behaviour (all related perspectives) or as a social problem (a quite different perspective).

For instance, a non-disease perspective on addiction includes two alternatives: If we regard addiction as a moral failing, we are likely to demand personal responsibility for dealing with the problem, and institute punitive approaches for those who fail (table 2). ${ }^{40} 42$ Alternatively, we may see addiction as a social problem and seek social solutions such as poverty reduction. ${ }^{44}$ The general unavailability of safe injection sites for drug users, despite evidence of benefit and eminent advocacy, illustrates how these issues play out in public policy. ${ }^{46}$ Our results suggest that the current contentious debate on social policy towards addiction could benefit not only from evidence regarding the effectiveness of alternative policies, but a more profound understanding of the biology and sociology of addiction.

To take other examples from table 2 with potentially negative consequences of a disease perspective, viewing social anxiety disorder or fibromyalgia as specific biological problems may lead to overdiagnosis and medical overtreatment, and undertreatment with behavioural approaches. ${ }^{15} 4549$ On the other hand, seeing these conditions as socially mediated adjustment problem risks stigmatisation and underuse of potentially effective medical treatment. ${ }^{15}{ }^{45}{ }^{49}$ For other states of being, the ongoing passionate debate has highlighted possible dangers in medicalising conditions that might be considered normal problems of living. ${ }^{14} 151731$

We found the association between considering a state of being a disease and readiness to fund treatment through public revenue very strong. If we consider obesity a disease, we might devote public funding to weight loss clinics. While this is true of very few jurisdictions, ${ }^{50}$ most highincome countries devote public funding to bariatric surgery for morbid obesity, a policy which-according to a Danish study ${ }^{34}$-many laypeople may question despite evidence suggesting that it is cost effective.

Advocates argue that placing a disease label on the absence of sexual desire is a step towards helping people ${ }^{39}$ while critics deem it a destructive medicalisation of a normal part of living fostering problematic commercialisation. ${ }^{41}$ Similarly, creating new diagnostic terms, such as the concept 'overactive bladder' may help to increase 
Table 2 Implications of alternative viewpoints regarding accepting or rejecting states of being as diseases

\section{Categories of states \\ of being}

Examples

Disease? Conceptualisation

Implications for action
Addictions or possible

addictions

Alcoholism

Drug addiction

Gambling addiction

Obesity

Smoking

Medical diagnoses with

uncertain biological/

psychosocial basis

Chronic fatigue syndrome No

Fibromyalgia

Irritable bowel syndrome

Panic disorder

Personality disorder

Diminished function or

altered appearance, often

age-related

Age-related muscle loss

Baldness

Yes

Biological health disorder

No

Lack of self-control

Moral failing

Social problem

Yes

Specific biological problem

Socially mediated adjustment problem

Biological health disorder

Erectile dysfunction

Lack of sexual desire

Patterns of behaviour

Homosexuality

Obesity

Smoking

Transsexualism

No

Syndromes or constellation of patterns of symptoms of unclear basis

Attention deficit

hyperactivity disorder

Fibromyalgia

Overactive urinary bladder

Panic disorder

Yes Biological health disorder

No Lifestyle choice disorder symptoms, signs, behaviours, label of convenience
Potential negative consequences/ ramifications

Harm reduction

Public funding

Medical treatment

Abstinence through individual choice and self-discipline

Punitive management strategies

Preventive social solutions:

income redistribution, poverty reduction,

education, social marketing

Diagnose and treat, possibly with drugs

Behavioural therapy

Modify environment

Diagnose and treat, possibly with drugs Public funding

Normal consequence of living Accept and adjust

Responsibility on individual

Diagnose and treat, possibly with drugs Negative social stigma

Respect person's choice

Abstinence/modification of behaviour through individual choice/self-discipline Punitive strategies

Yes Essentialist: specific biological

Label all patients with specific category and treat uniformly

Acknowledge syndromes as convenient constructions, seek underlying causes, don't attempt to pigeon-hole unusual presentations

Focus on individuals and treatments may cause social and moral aspects to be ignored ${ }^{8} 434447$

Stigma and discrimination, neglect of harm reduction, neglect of social causes, increased suffering for the population ${ }^{40} 42-444648$

Effective medical treatment underused ${ }^{42} 43$

Overdiagnosis and overtreatment with drugs, undertreatment with behavioural approaches ${ }^{11} 151631$

Patients may feel stigmatised

Effective medical treatment may be underused $^{111649}$

Overdiagnosis and overtreatment Medicalisation of society, with increased self-perception of illness and poorer coping with suffering that is part of life ${ }^{11}$ 15-17 49

Neglect of treatments that may reduce suffering and improve function ${ }^{11} 1649$

Adverse judgment and resulting stigma and discrimination ${ }^{53}$

Permissive attitude encourages self-destructive or morally reprehensible behaviour ${ }^{* 43}$

Underuse of effective treatment ${ }^{\star 34}$

Stigma and discrimination ${ }^{53}$

Failure to recognise diversity of illness, excessively uniform management, stifle research that could deepen understanding 2551 Acknowledgement of complexity may lead to inefficiency, paralysis ${ }^{2} 551$ 
awareness of the symptoms and to simplify management, but it may also cause problematic oversimplification leading to excessive use of ineffective treatment. ${ }^{55152}$

This discussion can also be seen from a more general perspective: essentialism versus nominalism (table 2). Essentialists regard diseases as causes of illness; the role of a physician, in this view, is to identify the cause and treat it appropriately. ${ }^{51}$ Nominalists see diseases as constructs that humans create to bring order to a disorderly world..$^{51}$

The concept of disease also helps us understand differing perspectives on patterns of behaviour (table 2), such as homosexuality. The American Psychiatric Association labeled homosexuality as a disease until 1973, when it was removed from its diagnostic and statistical manual of mental disorders (DSM). However, it remained in the ICD until 1992. ${ }^{53}$ Western societies increasingly view homosexuality as a legitimate lifestyle choice; less than $5 \%$ of doctors and nurses and less than $10 \%$ of laypeople and MPs in our survey considered homosexuality a disease. Our respondents likewise did not consider trans-sexualism a disease, contrary to the current ICD-10 classification. ${ }^{25}$ As with addiction, there is another non-disease perspective on sexual orientation: that homosexuality represents a moral failing. Historically, Western societies have deemed homosexual acts criminal behaviour. In many countries in the world, this continues to be the case.

\section{CONCLUSIONS}

In summary, the substantial disagreement we found in classifying of states of being as diseases, and the parallel disagreement regarding the legitimacy of public funding for those that warrant treatment provide insight into the attitudes underlying a number of current high profile social debates. The finding suggests that a shared understanding of the biological and social determinants of health conditions and human behaviours could be very useful in helping to facilitate the resolution of these debates.

\section{Author affiliations \\ ${ }^{1}$ Department of Clinical Epidemiology \& Biostatistics, McMaster University, Hamilton, Ontario, Canada \\ ${ }^{2}$ Department of Urology, Helsinki University Central Hospital and University of Helsinki, Helsinki, Finland \\ ${ }^{3}$ Insurance Division, State Treasury, Helsinki, Finland \\ ${ }^{4}$ Department of Medicine, McMaster University, Hamilton, Ontario, Canada \\ ${ }^{5}$ Department of Orthopaedics and Traumatology, Helsinki University Central Hospital and University of Helsinki, Helsinki, Finland}

Acknowledgements The authors thank Diane Heels-Ansdell and Brittany B Dennis for constructive comments on data analysis and interpretation of results, Virginia Mattila for linguistic expertise and language revisions, and Paula Hakkarainen, Kustaa Käki, Sanna Käki, Aura Matikainen, Kristiina Mellais, Dr Anita Pienimäki and Markku Viitamäki for support with data acquisition and/or constructive comments on study design and concept.

Contributors KAOT, JSL and TLNJ conceptualised the study. KAOT and TLNJ obtained funding. KAOT collected the data. KAOT and GHG developed the analysis plan with JSL, SE and TLNJ. KAOT analysed the data. All authors contributed to the interpretation of the results. KAOT and GHG led the writing of the manuscript; all authors contributed. All authors had full access to all the data and take responsibility for the integrity and the accuracy of the data All authors have approved the final version of the manuscript. KAOT is the guarantor.

Funding This study was supported by the Competitive Research Funding of the Pirkanmaa Hospital District (Tampere, Finland) grant numbers 9L033 and 9K043. The work of KAOT was supported by the Finnish Cultural Foundation and the Finnish Medical Foundation. The work of SE was supported by a Canadian Institutes of Health Research (CIHR) Doctoral Award. The funding sources had no role in design and conduct of the study; collection, management, analysis and interpretation of the data; and preparation, review, or approval of the manuscript. The authors' work was independent of the funders.

Competing interests JSL is a chief medical officer at the Insurance Division of the State Treasury (Helsinki, Finland), which is a government agency that handles statutory employment pension, accident and indemnity insurances and insurance-related employer services of government agencies.

Ethical approval In accordance with the Finnish regulations on questionnaire surveys, the ethics committee of the Pirkanmaa Hospital District in Finland granted exemption from ethical review (R11110).

Provenance and peer review Not commissioned; externally peer reviewed.

Data sharing statement Extra data can be accessed via the Dryad data repository at http://datadryad.org/ with the doi:10.5061/dryad.94qh5.

\section{REFERENCES}

1. Eisenberg L. Disease and illness. Distinctions between professional and popular ideas of sickness. Cult Med Psychiatry 1977;1:9-23.

2. Campbell EJ, Scadding JG, Roberts RS. The concept of disease Br Med J 1979;2:757-62.

3. Wulff HR. The concept of disease: from Newton back to Aristotle. Lancet 1999;354(Suppl):SIV50.

4. Temple LK, McLeod RS, Gallinger S, et al. Essays on science and society. Defining disease in the genomics era. Science 2001;293:807-8.

5. Pearce JM. Disease, diagnosis or syndrome? Pract Neurol 2011;11:91-7.

6. McWhinney IR. Health and disease: problems of definition. CMAJ 1987;136:815.

7. Seguin CA. The concept of disease. Psychosom Med 1946;8:252-7

8. Conrad P, Schneider JW. Deviance and medicalization: from badness to sickness. Philadelphia: Temple University Press, 1992.

9. Hinshaw SP, Cicchetti D. Stigma and mental disorder: conceptions of illness, public attitudes, personal disclosure, and social policy. Dev Psychopathol 2000;12:555-98.

10. Perry BL. The labeling paradox: stigma, the sick role, and social networks in mental illness. J Health Soc Behav 2011;52:460-77.

11. Smith R. In search of 'non-disease'. BMJ 2002;324:883-5.

12. Heath I. Who needs health care-the well or the sick? BMJ 2005;330:954-6.

13. Moynihan R. Medicalization. A new deal on disease definition. BMJ 2011;342:d2548.

14. Scully JL. What is a disease? EMBO Rep 2004;5:650-3.

15. Moynihan R, Heath I, Henry D. Selling sickness: the pharmaceutical industry and disease mongering. BMJ 2002;324:886-91.

16. Metzl JM, Herzig RM. Medicalisation in the 21st century: introduction. Lancet 2007;369:697-8.

17. Kleinman A. Culture, bereavement, and psychiatry. Lancet 2012;379:608-9.

18. Foucault M. The birth of the clinic: an archaeology of medical perception. New York: Pantheon Books, 1973.

19. Conrad P. Medicalization and social control. Annu Rev Socio 1992;18:209-32.

20. Padamsee TJ. The pharmaceutical corporation and the 'good work' of managing women's bodies. Soc Sci Med 2011;72:1342-50.

21. Parsons T. The Social System. New York: The Free Press, 1951

22. Shilling $\mathrm{C}$. Culture, the 'sick role' and the consumption of health. Br J Sociol 2002;53:621-38.

23. Parsons $\mathrm{T}$. The sick role and the role of the physician reconsidered. Milbank Mem Fund Q Health Soc 1975;53:257-78.

24. Meador CK. The art and science of nondisease. N Engl J Med 1965;272:92-5. 
25. International Statistical Classification of Diseases and Health Related Problems, version 10 (ICD-10). Geneva: World Health Organization. http://apps.who.int/classifications/icd10/browse/2010/ en (accessed 1 Feb 2012).

26. von Elm E, Altman DG, Egger M, et al. The Strengthening the Reporting of Observational Studies in Epidemiology (STROBE) statement: guidelines for reporting observational studies. BMJ 2007;335:806-8.

27. Tversky A, Kahneman D. The framing of decisions and the psychology of choice. Science 1981;211:453-8.

28. Gallagher KM, Updegraff JA. Health message framing effects on attitudes, intentions, and behavior: a meta-analytic review. Ann Behav Med 2012;43:101-16.

29. Mishra S, Gregson M, Lalumière ML. Framing effects and risk-sensitive decision making. Br J Psychol 2012;103:83-97.

30. Akl EA, Oxman AD, Herrin J, et al. Framing of health information messages. Cochrane Database Syst Rev 2011;CD006777.

31. Jones MP. What's a disease? Am J Gastroenterol 2003;98:2813-14.

32. Tang CH, Liu JT, Chang CW, et al. Willingness to pay for drug abuse treatment: results from a contingent valuation study in Taiwan. Health Policy 2007;82:251-62.

33. Perry BL, Pescosolido BA, Martin JK, et al. Comparison of public attributions, attitudes, and stigma in regard to depression among children and adults. Psychiatr Serv 2007;58:632-5.

34. Lund TB, Sandoe P, Lassen J. Attitudes to publicly funded obesity treatment and prevention. Obesity (Silver Spring) 2011;19:1580-5.

35. Stronks K, Strijbis AM, Wendte JF, et al. Who should decide? Qualitative analysis of panel data from public, patients, healthcare professionals, and insurers on priorities in health care. BMJ 1997;315:92-6.

36. Gross CP, Anderson GF, Powe NR. The relation between funding by the National Institutes of Health and the burden of disease. $N$ Engl $J$ Med 1999;340:1881-7.

37. Gillum LA, Gouveia C, Dorsey ER, et al. NIH disease funding levels and burden of disease. PLOS One 2011;6:e16837.

38. Hawkes N. NHS will soon have to specify what care is and what isn't freely available, GPs say. BMJ 2012;344:e1493.
39. Basson R, Berman J, Burnett A, et al. Report of the international consensus development conference on female sexual dysfunction: definitions and classifications. J Urol 2000;163:888-93.

40. Gandey A. US slams Canada over Vancouver's new drug injection site. CMAJ 2003;169:1063.

41. Moynihan R. The making of a disease: female sexual dysfunction. BMJ 2003;326:45-7.

42. Hyman SE. The neurobiology of addiction: implications for voluntary control of behavior. Am J Bioeth 2007;7:8-11.

43. Madueme $\mathrm{H}$. Addiction as an amoral condition? The case remains unproven. Am J Bioeth 2007;7:25-7.

44. Levy $\mathrm{N}$. The social: a missing term in the debate over addiction and voluntary control. Am J Bioeth 2007;7:35-6.

45. Henningsen P, Zipfel S, Herzog W. Management of functional somatic syndromes. Lancet 2007;369:946-55.

46. Lancet editorial board. HIV and injecting drug use: a global call for action. Lancet 2011;377:1212.

47. Moscrop A. Medicalisation, morality, and addiction: why we should be wary of problem gamblers in primary care. $\mathrm{Br} J$ Gen Pract 2011;61:e836-8.

48. McNeil DG Jr. An H.I.V. strategy invites addicts in. The New York Times, 16 Sept 2011. http://www.nytimes.com/2011/02/08/health/ 08vancouver.html?pagewanted=all (accessed 1 Feb 2012).

49. Broom DH, Woodward RV. Medicalisation reconsidered: a collaborative approach to care. Sociol Health IIIn 1996; 18:357-78.

50. Wharton S, VanderLelie S, Sharma AM, et al. Feasibility of an interdisciplinary program for obesity management in Canada. Can Fam Physician 2012;58:e32-8.

51. Scadding JG. Essentialism and nominalism in medicine: logic of diagnosis in disease terminology. Lancet 1996;348:594-6.

52. Tikkinen KA, Auvinen A. Does the imprecise definition of overactive bladder serve commercial rather than patient interests? Eur Urol 2012;61:746-8.

53. King M, Bartlett $\mathrm{A}$. British psychiatry and homosexuality. $\mathrm{Br} \mathrm{J}$ Psychiatry 1999;175:106-13. 